\title{
Awareness and differential eyeblink conditioning: effects of manipulating auditory CS frequencies
}

\author{
Anudeep Bolaram, ${ }^{1}$ Taylor E. Coe, ${ }^{1}$ John M. Power, ${ }^{2}$ and Dominic T. Cheng ${ }^{1}$ \\ ${ }^{1}$ Department of Psychology, Auburn University, Auburn, Alabama 36849, USA; ${ }^{2}$ Department of Physiology, University of New South \\ Wales, Sydney 2052, Australia
}

\begin{abstract}
The role of awareness in differential delay eyeblink conditioning $(\mathrm{EBC})$ has been a topic of much debate. We tested the idea that awareness is required for differential delay $E B C$ when two cues are perceptually similar. The present study manipulated frequencies of auditory conditioned stimuli (CS) to vary CS similarity in three groups of participants. Our findings indicate that awareness was not necessary for differential delay $E B C$ when two tones are easily discriminable, awareness was also not needed for relatively similar tones but may facilitate earlier conditioning, and awareness alone was not sufficient for differential delay EBC.
\end{abstract}

[Supplemental material is available for this article.]

Eyeblink classical conditioning (EBC) is one of the most extensively studied forms of mammalian learning and consequently, we have a detailed understanding of the behavioral processes and its underlying neural mechanisms (Gormezano 1966; Woodruff-Pak 1988; Christian and Thompson 2003). Typically, in EBC the conditioned stimulus (CS) is a neutral stimulus (e.g., tone) and the unconditioned stimulus (US) is a biologically meaningful stimulus (e.g., corneal airpuff) sufficient to elicit an unconditioned response (UR). Following repeated pairings of the CS and the US, the CS alone elicits an anticipatory eyeblink just before the occurrence of the airpuff. This eyeblink is termed the conditioned response (CR) and is taken as evidence that an association between the CS and US has been learned.

The role of awareness during human eyeblink classical conditioning has been a topic of much debate (LaBar and Disterhoft 1998; Lovibond and Shanks 2002; Manns et al. 2002). Some evidence suggests that reflexive eyeblink responses elicited by CSs do not rely on participants' explicit knowledge of the CS-US relationship, and therefore are independent of awareness (Clark and Squire 1998; Manns et al. 2001; Smith et al. 2005). Other studies indicate that awareness is necessary for successful EBC to take place (Knuttinen et al. 2001; Lovibond et al. 2011; Weidemann et al. 2013, 2016; Weidemann and Lovibond 2016). Various strategies, including masking procedures, demanding secondary tasks, and explicit instructions have been used to delay or prevent awareness during EBC (Carrillo et al. 2000; Weidemann et al. 2016).

In differential delay EBC, two tones are presented-one tone (CS+) is always followed by and coterminates with a corneal airpuff and the other tone (CS-) is never followed by an airpuff. Although this manipulation by itself may not significantly reduce participants' awareness, the combination of including a secondary task and presenting two CSs that are difficult to discriminate (e.g., perceptually similar) would make it more challenging for participants to accurately identify which CS predicted the US. The effects of CS discriminability on awareness and conditioning have been reported in fear conditioning studies (Knight et al. 2003; Schultz and Helmstetter 2010; Singh et al. 2013) but have

Corresponding author: dcheng@auburn.edu

Article is online at http://www.learnmem.org/cgi/doi/10.1101/lm.050146.119. not been directly investigated using EBC. While the majority of differential delay EBC studies used two distinct CSs (tone and white noise) that were fairly easy to discriminate, several have used two pure tones of varying frequencies as CSs and measured awareness (Ross and Nelson 1973; Nelson and Ross 1974; Huang et al. 2014). These studies found that awareness was needed for differential delay EBC although another study reports contradictory findings (Smith et al. 2005). This raises the possibility that awareness may be important for differential delay EBC when CSs are difficult to discriminate (e.g., two tones) but not needed when CSs are easily discriminable (Clark et al. 2002). Importantly, the frequencies presented in those studies may not have been too difficult to distinguish (e.g., $800 \mathrm{~Hz}$ vs. $2100 \mathrm{~Hz}$; $1000 \mathrm{~Hz}$ vs. $3000 \mathrm{~Hz}$ ), motivating further investigation of the idea that CS discriminability may be a factor in determining the necessity of awareness in differential EBC. The present study tested the general prediction that performance in differential delay EBC depends on contingency awareness when two tone CSs are relatively similar. In other words, only participants who are aware of the CS-US contingency will be able to show differential EBC to two perceptually similar CSs.

Sixty undergraduate students (54 female, mean age $=19.2$ yr) at Auburn University were recruited and randomly assigned to one of three groups. In Group I, CSs were $1000 \mathrm{~Hz}$ and a white noise, counterbalanced, and presented in a pseudorandom order such that no more than two trials of the same CS were consecutively presented. In Group II, CSs were 1000 and $1400 \mathrm{~Hz}$ and in Group III, CSs were 1000 and $1150 \mathrm{~Hz}$. CSs were presented at a volume of $85 \mathrm{~dB}$ for all participants. CS+ trials always coterminated with corneal airpuff ( 5 psi) US presentations and CS- trials were always presented alone (Fig. 1). Two hundred trials of two conditioned stimuli were presented (100 CS+ and 100 CS-). Participants were fitted with conditioning goggles and the experiment took place in a sound

\footnotetext{
C) 2020 Bolaram et al. This article is distributed exclusively by Cold Spring Harbor Laboratory Press for the first 12 months after the full-issue publication date (see http://learnmem.cshlp.org/site/misc/terms.xhtml). After 12 months, it is available under a Creative Commons License (AttributionNonCommercial 4.0 International), as described at http://creativecommons. org/licenses/by-nc/4.0/.
} 


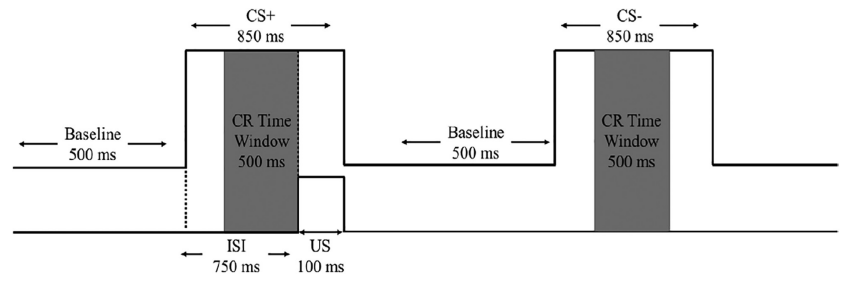

Figure 1. Timing of $C S+$ and $C S-$ trial types. Two hundred trials of two conditioned stimuli were presented (100 CS+ and $100 \mathrm{CS}-$ ). Each CS lasted $850 \mathrm{msec}$ and each trial lasted $2000 \mathrm{msec}$ with a variable intertrial interval (ITI) of 5-7 sec. Shaded areas indicate the time window that was sampled to classify eyeblinks as CRs. (CS) conditioned stimulus, (US) unconditioned stimulus, (CR) conditioned response, (ISI) interstimulus interval.

attenuated booth (see Supplemental Material). All participants were instructed to pay attention to a silent movie (on which they would be given a quiz) and informed that the tones and corneal airpuffs were distractors.

Immediately following conditioning, a 14-item questionnaire consisting of True/False statements was administered to assess participants' awareness of the CS-US contingency. This questionnaire was the same one used in a previous study (Manns et al. 2000) but given twice to assess awareness of both CS+ and CS- contingencies. In addition to the questionnaire, a schematic of a trial structure was presented to further probe the participants' understanding of the temporal sequence of events (Supplemental Fig. 1). Participants were asked to report at which time point (as indicated by letters in the schematic) the US occurred for $\mathrm{CS}+$ and CS-. Last, a True/False movie questionnaire was administered.

An eyeblink was considered a CR (Fig. 1) if the response amplitude within a $500 \mathrm{msec}$ time window before US onset was greater than four times the standard deviation of the baseline period (500 msec before CS presentation). These criteria were used to minimize the inclusion of spontaneous eyeblinks, orienting and voluntary responses (Spence and Ross 1959). Participants were categorized as aware if they scored at least 12 on the awareness questionnaire and correctly identified when/if the US was presented on the schematic for each CS. Performance was expressed as \% CR (number of CRs divided by the number of trials). Trials were grouped into five blocks with 20 trials/ block to assess learning-related changes.

An omnibus repeated measures analysis of variance (ANOVA) of Group (Group I, Group II, Group III) × CS Type $(\mathrm{CS}+, \quad \mathrm{CS}-) \times$ Awareness (Aware, Unaware) $\times$ Block (1-5) on \% CR was conducted using SPSS software (SPSS Version 24). This revealed a significant four-way interaction $\quad\left(F_{(8,216)}=2.96, \quad P=0.004\right)$. There was also a main effect of CS Type indicating overall greater responding to CS + compared to CS - trials $\left(F_{(1,54)}=\right.$ 30.77, $\left.P=1.0 \times 10^{-7}\right)$ and a significant CS Type $\times$ Group interaction effect $\left(F_{(2,54)}=\right.$ 5.01, $P=0.01$ ) (Fig. 2). Post hoc comparisons indicated that relative to Group I, Group II showed a significant increase in $\%$ CRs to CS - trials $\left(t_{(38)}=2.55, P=\right.$ $0.015)$ and Group III showed a trend $\left(t_{(38)}=1.90, P=0.065\right.$ ) (white bars in Fig. 2 ). There were no significant differences in \% CRs to CS+ across groups (all $P^{\prime} \mathrm{s}>0.05$ ). \% CRs within each group as a function of time (Blocks) is presented in Supplemental Figure 2 .

In order to assess the role of awareness within each Group, a CS Type $(\mathrm{CS}+, \mathrm{CS}-) \times$ Block $(1-5) \times$ Awareness (Aware, Unaware) repeated measures ANOVA on \% CR was conducted. Within Group I, a significant main effect of CS Type $\left(F_{(1,18)}=19.22, P=\right.$ $0.0001)$ and a CS Type $\times$ Block interaction $\left(F_{(4,72)}=3.04, P=\right.$ $0.022)$ were detected. Post hoc comparisons showed that both aware and unaware participants demonstrated significantly greater \% CRs to CS+ relative to CS- during Blocks 2-5 (all $P^{\prime} \mathrm{s}<0.05$ ). Furthermore, the interaction between CS Type and Awareness was not significant $\left(F_{(1,18)}=0.08, P=0.78\right)$ (Fig. 3A,B). Within Group II, a significant main effect of CS type was detected $\left(F_{(1,18)}=16.46\right.$, $P=0.001)$ but the interaction between CS Type and Block was not significant $\left(F_{(4,72)}=0.92, P=0.459\right)$. Similar to Group I, the interaction between CS Type and Awareness was not significant $\left(F_{(1,18)}=0.238, P=0.632\right)$. However, a three-way interaction between CS Type, Block, and Awareness was significant $\left(\mathrm{F}_{(4,72)}=\right.$ $6.389, P=0.0001)$. Post hoc comparisons showed that aware participants demonstrated significantly greater \% CRs to CS+ relative to CS- during Block $1\left(t_{(10)}=5.04, P=0.0005\right)$ and Block $2\left(t_{(10)}=3.50, P=0.006\right)$ while unaware participants demonstrated significantly greater \% CRs to CS+ relative to CS- during Block $3\left(t_{(8)}=3.65, P=0.006\right)$ and Block $5\left(t_{(8)}=3.47, P=0.008\right)$ as indicated by asterisks (Fig. 3C,D). There were no significant effects in Group III (all $P^{\prime} \mathrm{s}>0.05$ ) (Fig. 3E,F).

Pearson correlation coefficients between participants' awareness scores and their differential CR (\% CRs to CS+ minus \% CRs to CS-) were calculated for each group and none reached significance (all $P$ 's $>0.05$ ) (Supplemental Fig. 3). However, detecting a significant correlation between awareness and learning has been reported to be difficult (Vadillo et al. 2019).

Additional analyses were performed to rule out effects of nonassociative factors. There were no group differences in hearing thresholds, UR amplitudes, number of correctly answered movie questions, or number of correctly answered awareness questions (all $P^{\prime} \mathrm{s}>0.05$ ), suggesting that learning-related changes between groups were not due to differences in hearing ability, US processing, or general attention. Although there was no significant relationship between Group and the number of participants being classified as aware, a trend was observed $\left(\chi^{2}(2)=5.02, P=0.08\right)$.

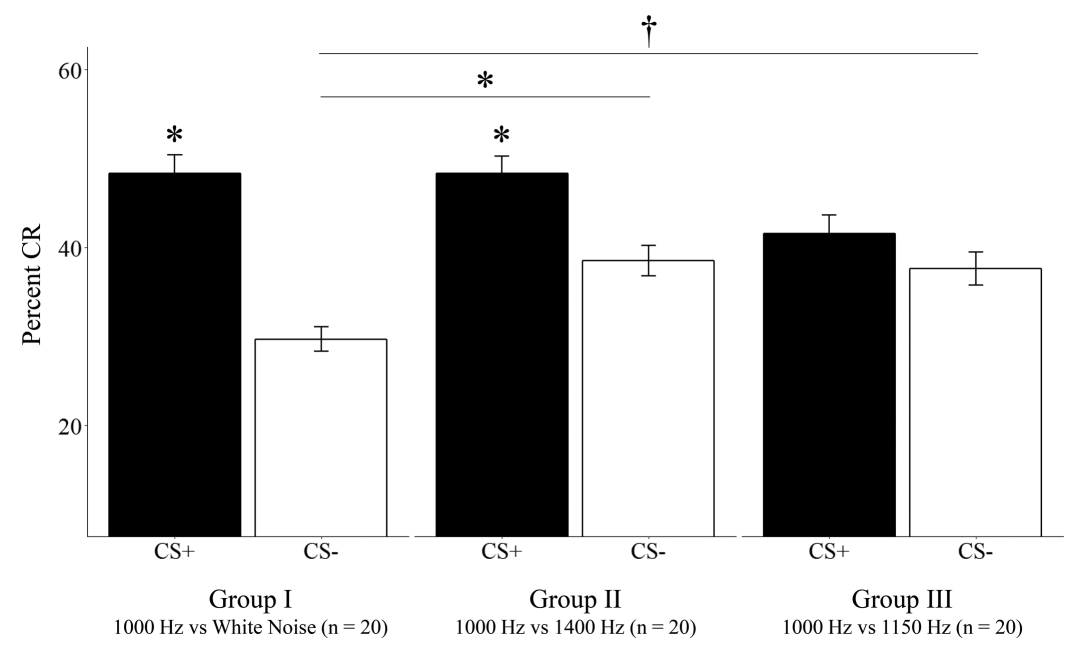

Figure 2. Overall \% CRs to CS+ and CS- trials for each group. Participants in Groups I and II showed significantly greater CRs to CS+ relative to CS- while participants in Group III did not. Relative to Group I, Group II showed greater \% CRs to CS- trials and Group III showed a trend. $\left(^{*}\right) P<0.05,(\dagger) P<0.07$. 

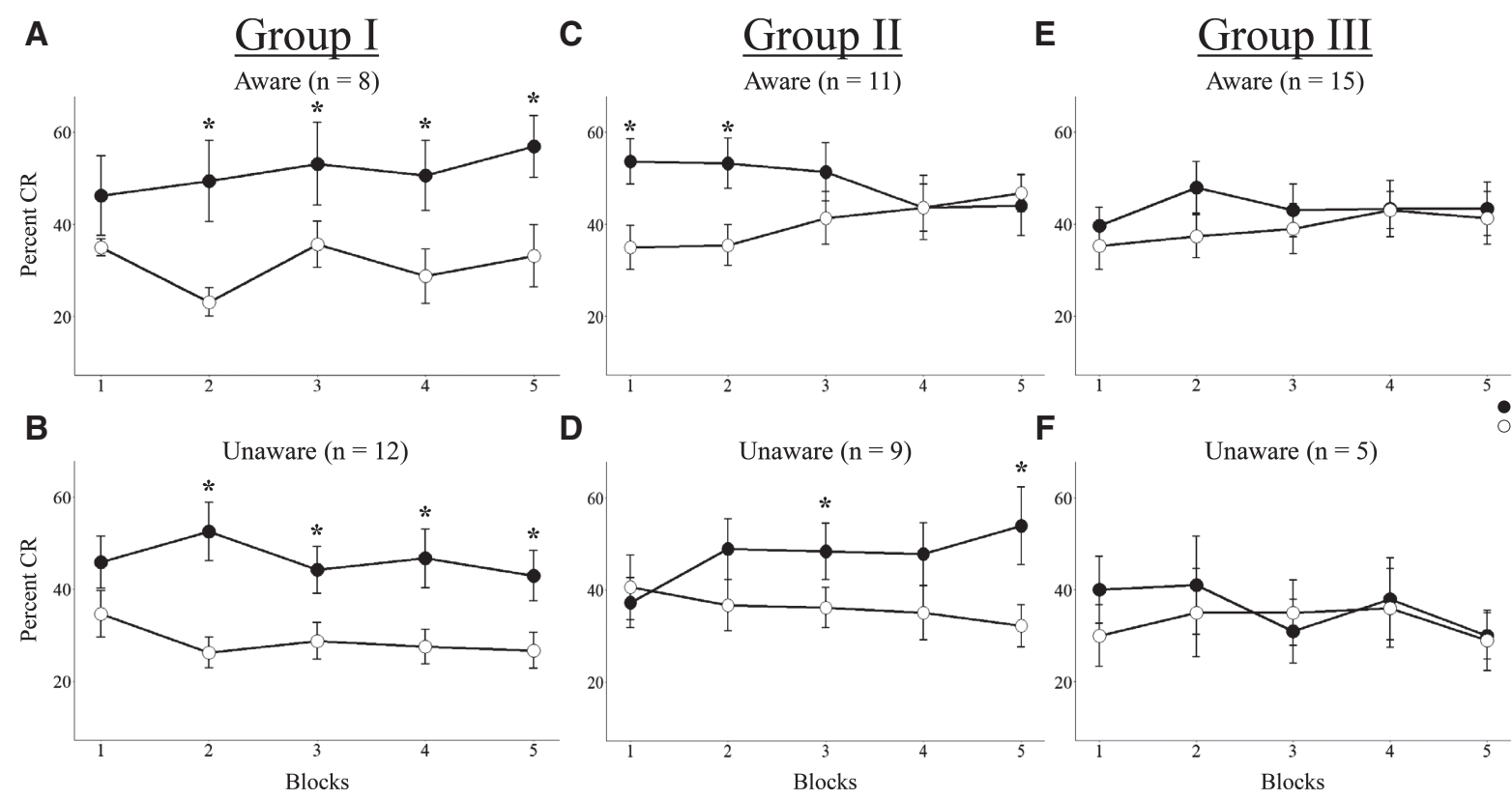

Figure 3. \% CRs broken down by group and awareness. $(A, B)$ Both aware and unaware Group I participants showed greater $\%$ CRs to $C S+$ relative to $C S-$ when CSs were distinct (1000 Hz vs. white noise). (C,D) Significantly greater \% CRs to CS+ relative to CS- was observed early (Blocks 1 and 2 ) for aware participants and later (Blocks 3 and 5) for unaware participants when CSs were similar (1000 Hz vs. $1400 \mathrm{~Hz})$. (E,F) No significant differences were detected when CSs were very similar $(1000 \mathrm{~Hz}$ vs. $1150 \mathrm{~Hz}) .\left({ }^{*}\right) P<0.05$.

Both aware and unaware participants were able to demonstrate differential conditioning when the CSs were a $1000 \mathrm{~Hz}$ tone and white noise (Group I), suggesting that awareness is not necessary for differential delay EBC when CSs are easy to discriminate (Fig. 3A,B). Similar studies using $1000 \mathrm{~Hz}$ tones and white noise as CSs have produced comparable findings as older and younger participants classified as unaware were able to acquire differential conditioning (Clark and Squire 1998, 1999; Smith et al. 2005). Furthermore, medial temporal lobe amnesics showed intact differential delay conditioning, despite not being able to explicitly report the CS-US relationship (Clark and Squire 1998). However, other studies using similar procedures have produced contradictory findings, suggesting that awareness is necessary for differential delay EBC (Carrillo et al. 2000; Knuttinen et al. 2001; Lovibond et al. 2011; Weidemann and Antees 2012). Knuttinen et al. (2001) performed an exhaustive series of experiments in older and younger adults using multiple interstimulus intervals and delay and trace procedures and found that awareness was important for successful differential conditioning. Furthermore, Lovibond et al. (2011) attempted to reproduce findings from Clark and Squire (1998) and Smith et al. (2005) by using a shorter postexperimental questionnaire and also found that only aware participants were able to show differential conditioning. Data from Group I indicate that awareness and conditioning are independent processes, but it is important to note several methodological differences (e.g., participant age, CS/US intensities, CR definitions to exclude voluntary eyeblinks, awareness measurements) between these studies as they may account for some of the divergent findings and should be considered when evaluating both sides of this debate.

While it has been shown that participants can show differential conditioning when CS+ and CS- frequencies differ by as little as $50 \mathrm{~Hz}$ (Moore 1964), this is the first EBC study to parametrically manipulate tone frequencies to vary CS discriminability to examine the role of awareness. In a series of experiments on visual CS similarity, acquisition rates in EBC and contingency learning were found to be comparable, suggesting these two processes are supported by a similar mechanism (Kinder and Lachnit 2003; Thorwart et al. 2010). A human fear conditioning study manipulated visual CS discriminability by presenting visual patterns (sine wave gratings) consisting of different spatial frequencies (Schultz and Helmstetter 2010). When participants were presented two similarly constructed visual CSs (one predicted shock and another predicted its absence), their online US expectancy to each CS did not differ (suggesting that they were unaware) but their skin conductance responses to the $\mathrm{CS}+$ was significantly greater than responses to the CS-, suggesting that autonomic fear CRs can occur without contingency awareness even when CSs are difficult to discriminate. Interestingly in Group II, aware participants showed early differential conditioning (Blocks 1 and 2) while unaware participants showed later differential conditioning (Block 5) (Fig. 3C, D). The finding that late differential EBC can occur without awareness when CSs are similar extend the study by Schultz and Helmstetter (2010) and suggest that unaware participants, when provided sufficient training, eventually show differential conditioning. Differential conditioning was not demonstrated by any participants in Group III, making it impossible to examine the necessary circumstances under which conditioning can occur when CSs are very similar $(1000 \mathrm{~Hz}$ vs. $1150 \mathrm{~Hz})$.

Across groups, participants showed different response patterns as a function of CS similarity. Specifically, this was characterized by a greater number of responses to CS- trials as CSs became more similar (white bars in Fig. 2). One possible interpretation of this effect is that overall associative strength assigned to the perceptually similar CSs shifted over the course of the experiment. This shift may have resulted in the CS- taking on some of the associative strength of the CS+, thereby eliciting responses to CS- (Rescorla and Wagner 1972). This could also explain why aware participants in Group II showed good differentiation early but their responses to $\mathrm{CS}+$ and CS- converged toward the end of the experiment (Fig. 3C). Another possibility is that the similarity of the CSs in Groups II and III facilitated CR generalization and participants mistakenly produced eyeblink responses to CS- trials that sounded 
similar to CS+ trials (Groups II and III) but not when the CS+ and CS- were easily discriminable (Group I). Spence's theory of discrimination learning (Spence 1937; Rilling 1977) states that responses acquired to CS+ and CS- during discrimination learning generalizes to stimuli that are close in dimension such that subsequent responding during generalization testing is a result of the interaction between responses to CS+ and CS-. Further formal generalization testing is needed in order to determine if this is indeed the case. Interestingly, it appeared that generalization did not apply in the case of awareness responses since all aware participants in Groups II and III reported hearing two different tones and correctly identified them as high and low pitch tones. Accordingly, it has been shown that repeated presentations of perceptually similar tones enhanced participants' ability to explicitly discriminate them (Ari-Even Roth et al. 2003; Wright and Zhang 2009). This dissociation of possible generalization of CRs but not awareness provides additional support that awareness and conditioning are mediated by independent processes and multiple memory systems.

Human memory has been classified into declarative and nondeclarative memory systems and is considered to be mediated by distinct neural substrates (Squire and Dede 2015). Declarative memory refers to memories related to facts (semantic memory) and events (episodic memory) that depends on conscious recollection of information. Procedural memory on the other hand does not require conscious awareness and can be manifested independently of the declarative memory system. EBC, specifically trace and delay paradigms have been utilized to investigate declarative and procedural aspects of memory. Results from Group I support the idea that awareness and conditioning are mediated by independent memory systems.

Despite no evidence of conditioning by participants who received very similarly sounding CSs (Group III), 75\% of these participants were still classified as aware. This suggests that awareness does not guarantee successful differential conditioning. This finding has also been reported in both eyeblink and fear conditioning studies (Dawson and Biferno 1973; Carrillo et al. 2000). A "necessary-gate" hypothesis about the relationship between awareness and autonomic conditioning has been proposed (Dawson and Furedy 1976). The main tenets of this hypothesis are that awareness of the CS-US contingency is imperative ("necessary"), but does not guarantee conditioning and that awareness happens in an all-or-none fashion ("gate") but also that the degree of awareness is not related to the degree of conditioning. Although results from Groups I and II argue against the "necessary" component of this hypothesis, behavior from Group III partially support this hypothesis in that $75 \%$ of the participants ( 15 out of 20 ) were classified as aware but failed to demonstrate differential conditioning (Fig. 3E), suggesting that awareness alone is not sufficient for conditioning. Consistent with this view and the present results, Nelson and Ross (1974) showed that explicitly informing participants the temporal relationship between the CS and US was not sufficient to elicit differential conditioning, suggesting that active attention to environmental contingencies and other cognitive factors are needed for successful differential conditioning. Furthermore, correlation analyses indicated that awareness scores did not predict differential responding in any of the three groups, consistent with this hypothesis' view that there is not a significant relationship between degree of awareness and level of conditioning.

Future work should consider some limitations of the present study. One methodological consideration among studies that investigate the role of awareness in conditioning is the method in which awareness is assessed. Two procedures are commonly used. First, a questionnaire designed to probe knowledge of the CS-US relationship is provided to participants following the condi- tioning session. This has disadvantages as it may not accurately reflect participants' awareness of the contingencies during conditioning (due to forgetting) and also does not indicate when participants became aware since these measurements are taken following the conditioning session. Another procedure is to require participants to provide an online US expectancy rating on a trial by trial basis during conditioning. One disadvantage of this technique is that it directs participants' attention to the US, which may have an unintentional effect on awareness and conditioning levels. This concurrent method of assessment also makes it difficult to distinguish between US expectancy awareness (i.e., knowing that a US is coming but not sure why) and contingency awareness (i.e., knowing that a US is coming and the reason why) (Lovibond and Shanks 2002). Another limitation is the relatively small number of participants when distributed among the six groups. Future studies should include additional participants to increase statistical power.

In summary, our data indicate that awareness was not necessary for differential delay EBC when two tones are easily discriminable (Group I), awareness was also not needed for similar tones but may facilitate earlier conditioning (Group II), and awareness alone was not sufficient for differential delay EBC (Group III).

\section{Competing interest statement}

The authors declare no competing financial interests.

\section{Acknowledgments}

This work was supported by a grant from the NIH/National Institute on Alcohol Abuse and Alcoholism K01 AA020873 (D.T.C.).

\section{References}

Ari-Even Roth D, Amir O, Alaluf L, Buchsenspanner S, Kishon-Rabin L. 2003. The effect of training on frequency discrimination: generalization to untrained frequencies and to the untrained ear. J Basic Clin Physiol Pharmacol 14: 137-150. doi:10.1515/jbcpp.2003.14.2.137

Carrillo MC, Gabrieli JDE, Disterhoft JF. 2000. Selective effects of division of attention on discrimination conditioning. Psychobiology 28: 293-302. doi:10.3758/bf03331988.

Christian KM, Thompson RF. 2003. Neural substrates of eyeblink conditioning: acquisition and retention. Learn Mem 10: 427-455. doi:10 $.1101 / \operatorname{lm} .59603$

Clark RE, Squire LR. 1998. Classical conditioning and brain systems: the role of awareness. Science 280: 77-81. doi:10.1126/science.280.5360.77

Clark RE, Squire LR. 1999. Human eyeblink classical conditioning: effects of manipulating awareness of the stimulus contingencies. Psychol Sci 10: 14-18. doi:10.1111/1467-9280.00099.

Clark RE, Manns JR, Squire LR. 2002. Classical conditioning, awareness, and brain systems. Trends Cogn Sci 6: 524-531. doi:10.1016/S1364-6613(02) 02041-7

Dawson ME, Biferno MA. 1973. Concurrent measurement of awareness and electrodermal classical conditioning. J Exp Psychol 101: 55-62. doi:10 .1037/h0035524

Dawson ME, Furedy JJ. 1976. The role of awareness in human differential autonomic classical conditioning: the necessary-gate hypothesis. Psychophysiology 13: 50-53. doi:10.1111/j.1469-8986.1976.tb03336.x

Gormezano I. 1966. Classical conditioning. In Experimental methods and instrumentation in psychology (ed. Sidowski JB), pp. 385-420. McGraw-Hill Book Co, New York.

Huang H, Wu B, Li Q, Yao J, Li X, Yang Y, Wu GY, Sui JF. 2014. Awareness is essential for differential delay eyeblink conditioning with soft-tone but not loud-tone conditioned stimuli. Neurosci Bull 30: 433-440. doi:10 .1007/s12264-013-1400-5.

Kinder A, Lachnit H. 2003. Similarity and discrimination in human Pavlovian conditioning. Psychophysiology 40: 226-234. doi:10.1111/ 1469-8986.00024.

Knight DC, Nguyen HT, Bandettini PA. 2003. Expression of conditional fear with and without awareness. Proc Natl Acad Sci 100: 15280-15283. doi:10.1073/pnas.2535780100. 
Knuttinen MG, Power JM, Preston AR, Disterhoft JF. 2001. Awareness in classical differential eyeblink conditioning in young and aging humans. Behav Neurosci 115: 747-757. doi:10.1037/0735-7044.115.4.747

LaBar KS, Disterhoft JF. 1998. Conditioning, awareness, and the hippocampus. Hippocampus 8: 620-626. doi:10.1002/(SICI)1098-1063 (1998)8:6<620::AID-HIPO4>3.0.CO;2-6

Lovibond PF, Shanks DR. 2002. The role of awareness in Pavlovian conditioning: empirical evidence and theoretical implications. J Exp Psychol Anim Behav Process 28: 3-26. doi:10.1037/0097-7403.28.1.3

Lovibond PF, Liu JC, Weidemann G, Mitchell CJ. 2011. Awareness is necessary for differential trace and delay eyeblink conditioning in humans. Biol Psychol 87: 393-400. doi:10.1016/j.biopsycho.2011.05 .002

Manns JR, Clark RE, Squire LR. 2000. Awareness predicts the magnitude of single-cue trace eyeblink conditioning. Hippocampus 10: 181-186. doi:10.1002/(SICI)1098-1063(2000)10:2<181::AID-HIPO7>3.0.CO;2-V

Manns JR, Clark RE, Squire L. 2001. Single-cue delay eyeblink conditioning is unrelated to awareness. Cogn Affect Behav Neurosci 1: 192-198. doi:10 .3758/CABN.1.2.192

Manns JR, Clark RE, Squire LR. 2002. Standard delay eyeblink classical conditioning is independent of awareness. J Exp Psychol Anim Behav Process 28: 32-37. doi:10.1037/0097-7403.28.1.32

Moore JW. 1964. Differential eyelid conditioning as a function of the frequency and intensity of auditory Css. J Exp Psychol 68: 250-259. doi: $10.1037 / \mathrm{h} 0040807$

Nelson MN, Ross LE. 1974. Effects of masking tasks on differential eyelid conditioning: a distinction between knowledge of stimulus contingencies and attentional or cognitive activities involving them. J Exp Psychol 102: 1-9. doi:10.1037/h0035682

Rescorla RA, Wagner AR. 1972. A theory of Pavlovian conditioning: variations in the effectiveness of reinforcement and nonreinforcement. In Classical conditioning II: current research and theory (ed. Black $\mathrm{AH}$, Prokasy WF), pp. 64-99. Appleton-Century-Crofts, New York.

Rilling M. 1977. Stimulus control and inhibitory processes. In Handbook of Operant Behavior (ed. Honig WK, Staddon JER), pp. 432-480. Prentice-Hall, Englewood Cliffs, NJ.

Ross LE, Nelson MN. 1973. The role of awareness in differential conditioning. Psychophysiology 10: 91-94. doi:10.1111/j.1469-8986 .1973.tb01089.x

Schultz DH, Helmstetter FJ. 2010. Classical conditioning of autonomic fear responses is independent of contingency awareness. J Exp Psychol Anim Behav Process 36: 495-500. doi:10.1037/a0020263.

Singh K, Dawson ME, Schell AM, Courtney CG, Payne AF. 2013. Can human autonomic classical conditioning occur without contingency awareness? The critical importance of the trial sequence. Biol Psychol 93: 197-205. doi:10.1016/j.biopsycho.2013.02.007.

Smith CN, Clark RE, Manns JR, Squire LR. 2005. Acquisition of differential delay eyeblink classical conditioning is independent of awareness. Behav Neurosci 119: 78-86. doi:10.1037/0735-7044.119.1.78.

Spence KW. 1937. The differential response in animals to stimuli varying within a single dimension. Psychol Rev 44: 430-444. doi:10.1037/ h0062885.

Spence KW, Ross LE. 1959. A methodological study of the form and latency of eyelid responses in conditioning. J Exp Psychol 58: 376-381. doi:10 $.1037 / \mathrm{h} 0045837$

Squire LR, Dede AJ. 2015. Conscious and unconscious memory systems. Cold Spring Harb Perspect Biol 7: a021667. doi:10.1101/cshperspect .a021667.

Thorwart A, Glautier S, Lachnit H. 2010. Convergent results in eyeblink conditioning and contingency learning in humans: addition of a common cue does not affect feature-negative discriminations. Biol Psychol 85: 207-212. doi:10.1016/j.biopsycho.2010.07.002.

Vadillo MA, Linssen D, Orgaz C, Parsons S, Shanks DR. 2019. Unconscious or underpowered? Probabilistic cuing of visual attention. J Exp Psychol Gen doi:10.1037/xge0000632.

Weidemann G, Antees C. 2012. Parallel acquisition of awareness and differential delay eyeblink conditioning. Learn Mem 19: 201-210. doi:10 $.1101 / \mathrm{lm} .024851 .111$.

Weidemann G, Lovibond PF. 2016. The role of US recency in the Perruchet effect in eyeblink conditioning. Biol Psychol 119: 1-10. doi:10.1016/j .biopsycho.2016.06.007.

Weidemann G, Best E, Lee JC, Lovibond PF. 2013. The role of contingency awareness in single-cue human eyeblink conditioning. Learn Mem 20: 363-366. doi:10.1101/lm.029975.112.

Weidemann G, Satkunarajah M, Lovibond PF. 2016. I think, therefore eyeblink: the importance of contingency awareness in conditioning. Psychol Sci 27: 467-475. doi:10.1177/0956797615625973.

Woodruff-Pak DS. 1988. Aging and classical conditioning: parallel studies in rabbits and humans. Neurobiol Aging 9: 511-522. doi:10.1016/ S0197-4580(88)80108-8

Wright BA, Zhang Y. 2009. A review of the generalization of auditory learning. Philos Trans R Soc Lond B Biol Sci 364: 301-311. doi:10.1098/ rstb.2008.0262.

Received June 13, 2019; accepted in revised form November 22, 2019. 


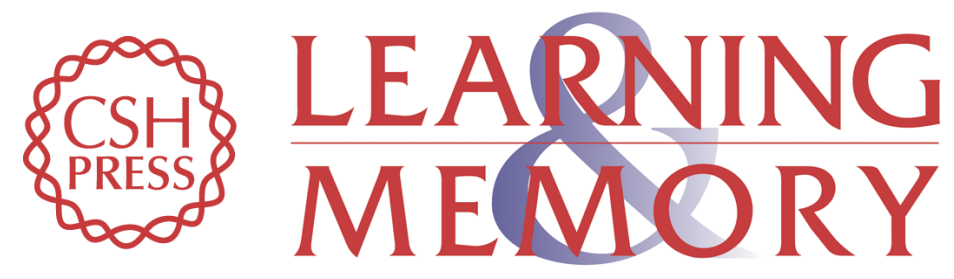

\section{Awareness and differential eyeblink conditioning: effects of manipulating auditory CS frequencies}

Anudeep Bolaram, Taylor E. Coe, John M. Power, et al.

Learn. Mem. 2020, 27:

Access the most recent version at doi:10.1101/Im.050146.119

\section{Supplemental http://learnmem.cshlp.org/content/suppl/2020/01/02/27.2.78.DC1 Material}

References This article cites 35 articles, 6 of which can be accessed free at: http://learnmem.cshlp.org/content/27/2/78.full.html\#ref-list-1

Creative This article is distributed exclusively by Cold Spring Harbor Laboratory Press for the Commons first 12 months after the full-issue publication date (see

License http://learnmem.cshlp.org/site/misc/terms.xhtml). After 12 months, it is available under a Creative Commons License (Attribution-NonCommercial 4.0 International), as described at http://creativecommons.org/licenses/by-nc/4.0/.

Email Alerting Receive free email alerts when new articles cite this article - sign up in the box at the Service top right corner of the article or click here. 